\title{
Diabetes and hypertension increases in a society with abdominal obesity: results of the Mexican National Health Survey 2000
}

\author{
Claudia P Sánchez-Castillo ${ }^{1, *}$, Oscar Velásquez-Monroy², Agustín Lara-Esqueda², \\ Arturo Berber ${ }^{3}$, Jaime Sepulveda ${ }^{4}$, Roberto Tapia-Conyer ${ }^{5}$ and W Philip T James ${ }^{6}$ \\ ${ }^{1}$ Instituto Nacional de Ciencias Médicas y Nutrición Salvador Zubirán, Dirección de Nutrición, Departamento de \\ Fisiología de la Nutrición, Vasco de Quiroga 15, Tlalpan, México 14000, DF: ${ }^{2}$ Centro Nacional de Vigilancia \\ Epidemiológica, Dirección del Programa de Salud del Adulto y el Anciano, Secretaría de Salud, México: ${ }^{3} \mathrm{Hospital}$ \\ Infantil de México 'Federico Gómez', México: ${ }^{4}$ National Health Survey 2000, México: ${ }^{5}$ Subsecretaría de \\ Prevención y Protección de la Salud, Secretaría de Salud, México: ${ }^{\circ}$ International Obesity Task Force, UK
}

Submitted 15 May 2003: Accepted 22 July 2004

\begin{abstract}
Objectives: To determine the prevalences of overweight, obesity, type 2 diabetes mellitus (DM) and hypertension (HT) in the Mexican population and compare them with those of a previous Mexican urban survey and an American survey.

Design: A structured, randomised, nationally representative Mexican sample was compared with a 1993 Mexican urban survey and the US Third National Health and Nutrition Examination Survey (NHANES III) of non-Hispanic Whites.

Setting: The Mexican National Health Survey 2000.

Subjects: Subjects were 12856 men and 28332 women, aged 20-69 years, who had their body weight, height, waist circumference (WC), blood pressure and fasting capillary blood glucose measured.

Results: Mexican adult men and women had a high prevalence of overweight ( 41.3 and $36.3 \%$, respectively) and obesity (19.4 and 29.0\%, respectively), similar to those in the USA in 1988-1992 and exceeding those of the 1993 Mexican survey. The prevalence of HT was 33.3\% in men and $25.6 \%$ in women, with inferred DM rates of 5.6 and $9.7 \%$, respectively. Abdominal obesity affected $46.3 \%$ of men (WC $\geq 94 \mathrm{~cm}$ ) and $81.4 \%$ of women (WC $\geq 80 \mathrm{~cm}$ ). There was a high prevalence of abdominal obesity in normal-weight women, with co-morbidities relating better to WC than to body mass index (BMI) in both sexes. Rates of DM and HT exceeded US rates on a comparable BMI or WC basis in adults aged $<50$ years.

Conclusion: The high prevalence of obesity and abdominal obesity in Mexicans is associated with markedly increased prevalences of DM and HT to levels comparable with, or even higher than, those in NHANES III of non-Hispanic Whites.
\end{abstract}

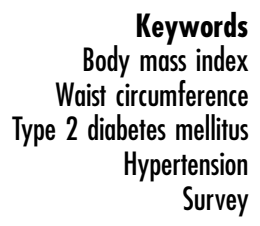

Keywords

Body mass index

Waist circumference

Hypertension

Survey
Mexico is a country that has been classified as having reached a complete epidemiological transition, i.e. with a moderate birth rate, a moderate or low mortality rate, moderate population growth $(2.0 \%)^{1}$ and increased prevalences of chronic diseases. Adults now comprise more than half the population and the diseases affecting this group constitute the main causes of death.

Mexico's health concerns have traditionally been those of childhood malnutrition and infectious disease. Recent surveys in several parts of Mexico in 1998-1999 revealed a persisting prevalence of childhood stunting among the under- 5 s of $17.8 \%$ compared with $22.8 \%$ in $1988^{2}$. There is also still major concern about the high prevalence of irondeficiency anaemia, which affects $26.2 \%$ of pregnant and $20 \%$ of non-pregnant women between the ages of 12 and
49 years $^{2}$, together with the high prevalences of folate and vitamin $\mathrm{B}_{12}$ deficiency ${ }^{3}$ and low intakes of retinol $^{4}$, riboflavin and niacin ${ }^{5-8}$. These deficiencies are particularly associated with the poor diets of the rural communities. Recently, however, mortality statistics have revealed that cardiovascular diseases (CVD), diabetes mellitus (DM) and cancers have in the last 30 years overtaken infectious diseases as the principal cause of death ${ }^{9}$. In 1993, a survey of adults in the major towns and cities ${ }^{10,11}$ showed a surprisingly high prevalence of obesity by current World Health Organization (WHO) criteria. Thus $14.9 \%$ of men and $25.1 \%$ of women had body mass index (BMI) $\geq 30 \mathrm{~kg} \mathrm{~m}^{-2}$, with DM rates assessed by fasting and non-fasting capillary glucose to be $7.2 \%$ in adults. The prevalence of hypertension (HT) was also 
high: $28.5 \%$ and $25.1 \%$ in men and women, respectively, with an $8.8 \%$ prevalence of hypercholesterolaemia (i.e. $\geq 5.2 \mathrm{mmoll}^{-1}$ ) in those older than 20 years and the clear emergence of coronary heart disease (CHD) as a major problem.

Deaths from CVD increased markedly from 3.7\% of total deaths in the 1940 s to $21 \%$ by the $1990 \mathrm{~s}^{10}$; the prevalences of DM, HT and CHD increase with age, and in the group aged 65-69 years HT and DM are now major problems. It is also suggested that there is a genetic susceptibility to insulin resistance, obesity and type 2 DM in Mexican and Mexican Americans related to their Amerindian heritage ${ }^{12}$. While this may reflect the impact of a high prevalence of a thrifty genotype, there may also be maternal factors including multiple nutritional deficiencies which induce epigenetic changes in utero and during postnatal life ${ }^{13}$. The 1999 National Nutrition Survey also found high prevalences of overweight and obesity in girls and women aged 12-49 years $^{2}$. On this basis the Ministry of Health (Secretaría de Salud) decided to undertake a nationally representative survey in the year 2000 of children and adults to assess their health status. In this analysis we present the results in adults and assess whether overweight and abdominal or general obesity are linked with the prevalence of DM and HT; the data are then compared with the previous survey and comparable data from the USA.

\section{Materials and methods}

A random sample of Basic Geographical Statistical Units was obtained in each state and in Mexico City from a database periodically updated by the Instituto Nacional de Geografía y Estadística (National Institute of Geography and Statistics). The sampling was based on a probabilistic cross-sectional survey in households including questionnaires, in situ measurements and blood sample collection. Two adult members in all households of the selected blocks were surveyed with the exception of those living in military, religious, health and other institutions. A detailed description of the sample frame has been given elsewhere $^{14}$ and analyses showed that those sampled were representative of the national population, although there was a lower sampling rate for men because many were at work at the time of the survey. The adult sample was statistically adjusted to the structure of the Mexican population aged 20-69 years in the 2000 census $^{15}$. The data presented here were collected in the Mexican National Health Survey 2000 (ENSA 2000) and include regional differences with a sample which is representative of each state ${ }^{14}$.

All procedures were in accordance with the ethical standards of the Committee of the Mexican National Institutes of Health on human experimentation and with the Helsinki Declaration of 1975, as revised in 1983. An individual questionnaire was used to obtain information on age, family history, clinical symptoms and medical treatment for various chronic diseases. Demographic data were collected and for this analysis data from 41188 households were used. In total 12856 men and 28332 women were measured; the age distribution of the sample was similar to the census data except that there was a slightly higher proportion of men and women over the age of 50 years. Thus the sampling system based on having households with children did not selectively limit access to the elderly.

Height was measured to the nearest $5 \mathrm{~mm}$ (Estadimeter SECA; Productos ADEX, SA de CV, Mexico) and weight to the nearest $0.1 \mathrm{~kg}$ (Solar Scale; Tanita Corporation of America, Inc., Arlington Heights, IL, USA) with the subject in light clothing without shoes. BMI was calculated as weight $(\mathrm{kg})$ divided by the square of height $(\mathrm{m})$. Waist circumference (WC) was measured at the midpoint between the highest point of the iliac crest and the lowest part of the costal margin at the mid-axillary line, to the nearest $0.1 \mathrm{~cm}$. After sitting for at least $5 \mathrm{~min}$, blood pressure (BP) was measured in the right arm by the research nurse using a standard aneroid sphygmomanometer (Productos Adex, SA de CV, Mexico). The Korotkoff sound V was taken as the diastolic BP. Casual and fasting samples of capillary glucose were also obtained. Capillary blood was taken with a glucose meter (Accutrend Sensor Comfort; Roche Diagnostic Corporation, Indianapolis, IN, USA), note being taken of whether it was fasting or not.

For the present comparisons, the diagnosis of diabetes was based on the criteria of the American Diabetes Association $^{16}$. Thus the number of persons with diabetes was defined as including recognised and treated patients with type $2 \mathrm{DM}$ and those with fasting capillary blood glucose values $\geq 126 \mathrm{mg} \mathrm{dl}^{-1}$. In view of the relatively small number of subjects with fasting glucose values, both the Mexican and US data were age-standardised for all adults when assessing the relationship of DM to BMI and WC. However, owing to the greater number of subjects with HT, defined as those currently taking hypertensives for treatment of HT and those with systolic BP $\geq 140 \mathrm{mmHg}$ and/or diastolic BP $\geq 90 \mathrm{mmHg}^{17}$, the BMI and WC relationships could be compared in three age groups. Only the non-Hispanic US Whites from the US Third National Health and Nutrition Examination Survey (NHANES III), adjusted to standardise to the Mexican 2000 population structure, formed the comparator group.

Statistical analysis was performed using the Statistical Package for Social Sciences (version 9.0) software (SPSS Inc., Chicago, IL, USA) on an IBM-compatible computer. All databases were adjusted to the structure of the Mexican population in the 2000 census. Mean and standard deviations were calculated for scale variables while frequencies and percentages were calculated for nominal and categorical variables. BMI values were categorised to the corresponding unit and the prevalence for DM and HT was calculated for each BMI value. WC values were 
categorised as 70-74, 75-79, 80-89, 90-94, 95-100, 101105 and $>105 \mathrm{~cm}$ and the prevalences of DM and HT were calculated for each group. Thus both BMI and WC were considered across the range of values rather than just in categorical terms based on WHO criteria, which for WC was specified as relating to subjects of Caucasian stock.

Factor analysis ${ }^{18}$ with a standard procedure (SPSS version 9.0) was used to calculate commonalities (proportion of shared variance) for waist, BMI, age and height. Factor analytic techniques are used to reduce the number of variables, to detect structure in the relationships between variables, and to classify variables. Therefore, factor analysis is applied as a data reduction or structure detection method. Factor analysis could thus be successfully employed to identify a small number of underlying DM or HT risk patterns, which explained most of the variance observed in a much larger number of risks. With the factor analysis, it was possible to investigate the number of various subgroups or factors and to identify what these subgroups represent conceptually. Factor analysis consists of three steps: computation of a correlation matrix for all variables included; factor extraction; and orthogonal rotation to make factors more readily interpretable. Factors were extracted by principal components analysis, in which linear combinations of the variables are formed, with the first principal component accounting for the largest amount of variance in the sample. The components are all uncorrelated. Factor loadings, equivalent to a Pearson's correlation coefficient between each variable and the factor, are used to interpret which variables are included in each factor. Factor loadings greater than or equal to 0.4 , which share at least $15 \%$ of variance with the factor, were used in interpretation and analysis. The factor loading indicates the importance of a variable in the definition of the pattern. Factors were selected according to Kaiser's criterion $^{18}$ (eigenvalue $\geq 1$ ), which chooses only factors explaining more than the average variance of factors. A factor with a high eigenvalue is one that can be held accountable for a significant amount of variance. In addition, we required that each factor have more than two variables with loadings $\geq|0.4|$.

All results are expressed as mean \pm standard deviation or a percentage where appropriate. The criterion for specifying overweight was BMI of $25.0-29.9 \mathrm{~kg} \mathrm{~m}^{-2}$, with obesity specified as BMI of $30.0 \mathrm{~kg} \mathrm{~m}^{-2}$ or more ${ }^{19}$. The attributable risk of higher BMIs was calculated with the following formula:

\section{Attributable \% DM or HT}

$$
=\frac{\left(\begin{array}{c}
\% \text { DM or HT prevalence in higher BMIs } \\
-\% \text { DM or HT prevalence in lower BMIs }) \\
\times \text { total population with higher BMIs }
\end{array}\right)}{\text { total number of DM or HT cases }}
$$

The attributable risks were evaluated at progressively higher BMI thresholds.

\section{Results}

The studied population consisted of 12856 men and 28332 women in the age groups set out in Table 1 . This table also includes data on weight, height, WC and BMI, which are shown along with the prevalences of overweight, obesity, DM and HT for each age group. Adult men had greater weight, height and WC than the women, but not the same distribution pattern of BMI. Thus $41.3 \%$ of the men and $36.2 \%$ of women were overweight but more women (29\%) were obese than were men (19.4\%). Among men, 24.1\% had WC from 94 to $101.9 \mathrm{~cm}$ (waist action level 1 according to $\mathrm{WHO}^{19}$ criteria) and a further $22.2 \%$ had WC $>102.0 \mathrm{~cm}$ (waist action level 2). In women, $20.8 \%$ had WC from 80.0 to $87.9 \mathrm{~cm}$ (waist action level 1), but another $60.6 \%$ had WC $>88.0 \mathrm{~cm}$ (waist action level 2). The oldest group had lower BMI but nevertheless had marked increases in WC. The overall prevalences of type $2 \mathrm{DM}$, based on fasting values, were high: $5.6 \%$ in men and $9.7 \%$ in women. Hypertension was also

Table 1 Anthropometric variables (mean \pm standard deviation) and prevalences of overweight (body mass index (BMI) 25.0$29.9 \mathrm{~kg} \mathrm{~m}^{-2}$ ) and obesity (BMI $\left.>30 \mathrm{~kg} \mathrm{~m}^{-2}\right)$, type 2 diabetes mellitus (DM) and hypertension in the male and female population* from the National Health Survey, 2000, in Mexico

\begin{tabular}{|c|c|c|c|c|c|c|c|c|}
\hline $\begin{array}{l}\text { Age group } \\
\text { (years) }\end{array}$ & Height (m) & Weight (kg) & $\mathrm{BMI}\left(\mathrm{kg} \mathrm{m}^{-2}\right)$ & Waist (cm) & $\begin{array}{l}\text { Overweight } \\
(\%)\end{array}$ & Obese (\%) & DM (\%) & $\begin{array}{c}\text { Hypertension } \\
(\%)\end{array}$ \\
\hline \multicolumn{9}{|l|}{ Men } \\
\hline $20-29$ & $1.67 \pm 0.08$ & $70.7 \pm 14.3$ & $25.2 \pm 4.4$ & $88.3 \pm 13.4$ & 34.3 & 12.0 & 0.9 & 20.5 \\
\hline $30-39$ & $1.66 \pm 0.08$ & $74.7 \pm 14.5$ & $27.0 \pm 4.5$ & $93.6 \pm 13.0$ & 45.7 & 21.2 & 6.5 & 32.3 \\
\hline $40-49$ & $1.65 \pm 0.07$ & $75.4 \pm 14.0$ & $27.5 \pm 4.4$ & $96.5 \pm 13.0$ & 46.6 & 24.4 & 5.7 & 41.8 \\
\hline $50-59$ & $1.64 \pm 0.08$ & $74.6 \pm 15.0$ & $27.5 \pm 5.0$ & $97.5 \pm 13.4$ & 43.0 & 25.6 & 14.5 & 46.4 \\
\hline $60-69$ & $1.63 \pm 0.07$ & $72.2 \pm 14.8$ & $27.1 \pm 5.0$ & $98.5 \pm 14.1$ & 41.3 & 24.0 & 24.1 & 52.4 \\
\hline \multicolumn{9}{|l|}{ Women } \\
\hline $20-29$ & $1.54 \pm 0.07$ & $61.5 \pm 13.1$ & $25.8 \pm 5.1$ & $86.4 \pm 14.5$ & 32.3 & 17.4 & 2.9 & 11.3 \\
\hline $30-39$ & $1.54 \pm 0.07$ & $66.2 \pm 14.1$ & $27.9 \pm 5.5$ & $92.4 \pm 14.4$ & 38.3 & 29.9 & 5.1 & 17.8 \\
\hline $40-49$ & $1.53 \pm 0.06$ & $68.1 \pm 14.1$ & $29.1 \pm 5.6$ & $96.9 \pm 14.5$ & 38.5 & 39.3 & 14.6 & 33.2 \\
\hline $50-59$ & $1.51 \pm 0.06$ & $67.4 \pm 14.1$ & $29.3 \pm 5.6$ & $100.7 \pm 15.4$ & 39.2 & 40.1 & 23.6 & 52.5 \\
\hline $60-69$ & $1.50 \pm 0.07$ & $65.1 \pm 15.2$ & $28.8 \pm 6.1$ & $101.2 \pm 14.0$ & 37.2 & 35.9 & 38.2 & 57.7 \\
\hline
\end{tabular}

* Figures are adjusted to the national total population based on the state censuses in 2000. 


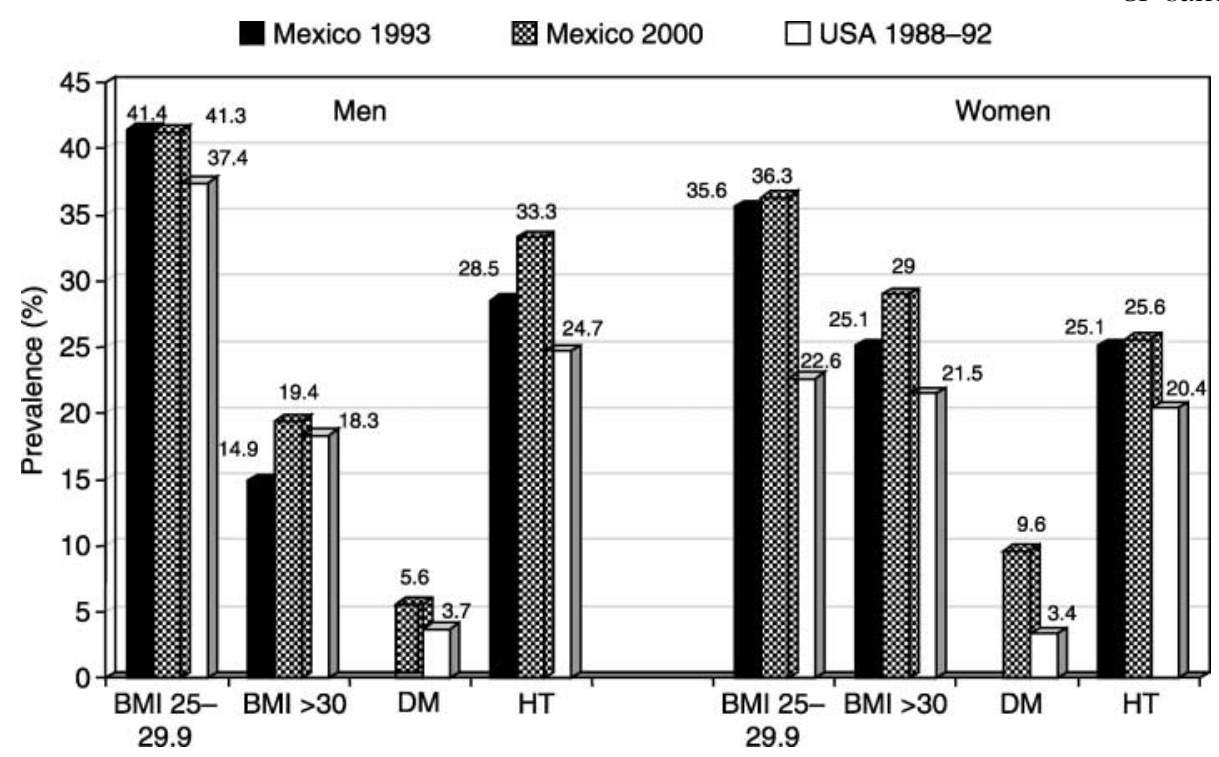

Fig. 1 Age-standardised prevalences of overweight (body mass index (BMI) 25-29.9 $\mathrm{kg} \mathrm{m}^{-2}$ ), obesity (BMl $>30 \mathrm{~kg} \mathrm{~m}^{-2}$ ), hypertension (HT) and type 2 diabetes mellitus (DM): comparison between an urban Mexican population in 1993, the total Mexican population in 2000 and US non-Hispanic Whites in 1988-1992

prevalent: $33.3 \%$ in men and $25.6 \%$ in women, in keeping with substantial stroke rates in $\mathrm{Mexico}^{20}$. The comorbidities of obesity rose markedly with age, so that about $16 \%$ of all those over 50 years had DM and about $45 \%$ had HT. When the urban population was selected, their overweight and obesity prevalences were 42.5 and $23.9 \%$ respectively in men and 36.1 and $31.8 \%$ respectively in women.

Figure 1 compares the current data with those found in the 1993 Mexican urban survey and in the US NHANES III of non-Hispanic White adults, with the values adjusted to the Mexican population census. DM rates are not shown for the 1993 Mexican urban survey because these were estimated from both random fasting and non-fasting capillary glucose measurements with subgroups tested with glucose tolerance tests. On this basis, $7.2 \%$ of urban Mexican adults were specified as having DM in 1993. Applying the same assumptions to the current survey suggests that $5.8 \%$ of men and $9.4 \%$ of women - i.e. $7.6 \%$ of the overall population of both urban and rural adults now have DM. On the basis of fasting glucose levels only to allow comparisons with the US data, current Mexican DM prevalences as well as overweight, obesity and HT rates all exceeded those observed in US non-Hispanic Whites in the early 1990s.

Table 2 shows the prevalence of DM according to both $\mathrm{BMI}$ and WC for men and women separately. Included are comparably recalculated data from the US NHANES III of non-Hispanic White adults, which revealed higher BMIand WC-related DM prevalences in Mexican than in US adults with marked differences among women. It is evident that body weight, expressed as BMI, is an important predictor of the prevalences of DM and HT. Thus, given the high prevalence of obesity in the
Table 2 Prevalence of diabetes assessed in relation to body mass index (BMI) and waist circumference (WC): comparison between Mexican men and women aged 20-69 years from the National Health Survey, 2000 and similar age-adjusted data from the US Third National Health and Nutrition Examination Survey of non-Hispanic Whites

\begin{tabular}{|c|c|c|c|c|}
\hline & \multicolumn{2}{|c|}{ Men } & \multicolumn{2}{|c|}{ Women } \\
\hline & Mexico & USA & Mexico & USA \\
\hline \multicolumn{5}{|l|}{ BMI $\left(\mathrm{kg} \mathrm{m}^{-2}\right)$} \\
\hline $21-22$ & $4.3^{*}$ & 0.4 & $6.4^{*}$ & 0.3 \\
\hline $23-24$ & 1.2 & 1.4 & 5.1 & 3.4 \\
\hline $25-26$ & $6.1^{*}$ & 2.2 & $6.8^{*}$ & 1.1 \\
\hline $27-28$ & $9.7^{*}$ & 3.9 & $10.8^{*}$ & 6.2 \\
\hline $29-30$ & 4.7 & 6.9 & $13.0^{*}$ & 5.0 \\
\hline$>30$ & 10.6 & 11.5 & $17.3^{*}$ & 10.4 \\
\hline \multicolumn{5}{|l|}{$W C(\mathrm{~cm})$} \\
\hline $70-74$ & $3.9^{*}$ & 0.0 & $7.7^{*}$ & 0.0 \\
\hline $75-79$ & $5.9^{*}$ & 0.4 & 0.8 & 0.2 \\
\hline $80-84$ & 1.0 & 1.0 & 4.3 & 2.5 \\
\hline $85-89$ & $5.0^{*}$ & 0.1 & $6.6^{\star}$ & 3.3 \\
\hline $90-94$ & $6.4^{*}$ & 1.0 & $11.9^{*}$ & 2.8 \\
\hline $95-99$ & 2.9 & 1.6 & $9.2^{*}$ & 4.6 \\
\hline $100-104$ & 11.9 & 8.5 & 11.9 & 9.4 \\
\hline $105+$ & 9.9 & 10.9 & $21.7^{*}$ & 11.9 \\
\hline
\end{tabular}

* Significant difference between national groups: $P<0.05$. The overall diabetes prevalences were $0,2.6$ and $13.8 \%$ in $20-29-, 30-49-$ and $50-69$ year-old US men, respectively, compared with $0.8,6.4$ and $16.7 \%$ in Mexican men. Comparable prevalences for US women were 1.3, 2.6 and $9.3 \%$ compared with 2.6, 9.2 and $29.6 \%$ for Mexican women.

middle-aged (Table 1), it is perhaps to be expected that 16.7 and $29.6 \%$ of Mexican men and women over 50 years old had type 2 DM compared with $13.8 \%$ of US men and $9.3 \%$ of US women of similar age $\mathrm{e}^{21}$. The relationship of DM to WC also revealed higher prevalence rates of $\mathrm{DM}$ in Mexican than in US adults at comparable WC values.

Table 3 shows data for HT according to BMI and WC for men and women separately. The prevalence of HT in 
Table 3 Prevalence of hypertension assessed in relation to body mass index (BMI) and waist circumference (WC) and according to age: comparison between Mexican men and women aged 20-69 years from the National Health Survey, 2000 and similar age-adjusted data from the US Third National Health and Nutrition Examination Survey of non-Hispanic Whites

\begin{tabular}{|c|c|c|c|c|c|c|c|c|c|c|c|c|}
\hline & \multicolumn{6}{|c|}{ Men } & \multicolumn{6}{|c|}{ Women } \\
\hline & \multicolumn{2}{|c|}{$20-29$ years } & \multicolumn{2}{|c|}{$30-49$ years } & \multicolumn{2}{|c|}{$50-69$ years } & \multicolumn{2}{|c|}{$20-29$ years } & \multicolumn{2}{|c|}{$30-49$ years } & \multicolumn{2}{|c|}{$50-69$ years } \\
\hline & Mexico & USA & Mexico & USA & Mexico & USA & Mexico & USA & Mexico & USA & Mexico & USA \\
\hline \multicolumn{13}{|l|}{ BMI $\left(\mathrm{kg} \mathrm{m}^{-2}\right)$} \\
\hline 22 & $20.0^{*}$ & 4.0 & 26.1 & 11.8 & 39.7 & 42.1 & 6.0 & 5.9 & 12.5 & 10.2 & $43.8^{*}$ & 28.9 \\
\hline 23 & $13.0^{*}$ & 18.5 & $22.3^{*}$ & 15.8 & 26.6 & $35.4^{*}$ & $9.3^{*}$ & 6.5 & $12.8^{*}$ & 9.4 & 42.1 & 36.8 \\
\hline 24 & $16.7^{*}$ & 8.9 & $23.5^{\star}$ & 13.8 & 42.7 & 38.3 & 9.4 & 9.0 & $15.5^{\star}$ & 12.2 & 47.3 & 40.5 \\
\hline 25 & $20.0^{\star}$ & 14.9 & $30.5^{\star}$ & 25.1 & 46.2 & 49.8 & 9.1 & 7.3 & $16.4^{*}$ & 14.0 & $43.1^{*}$ & 41.0 \\
\hline 26 & $21.0^{*}$ & 6.3 & $30.4^{*}$ & 24.9 & $55.8^{*}$ & 31.4 & 10.1 & 9.9 & 20.1 & 12.5 & 52.3 & 41.9 \\
\hline 27 & $22.5^{\star}$ & 5.0 & $38.0^{*}$ & 21.0 & 52.2 & 47.1 & 9.5 & 11.1 & 20.9 & 20.7 & $47.5^{\star}$ & 39.2 \\
\hline 28 & $26.8^{\star}$ & 14.8 & $40.5^{\star}$ & 31.6 & 44.8 & 46.4 & $14.3^{*}$ & 6.3 & $21.3^{\star}$ & 16.5 & $56.4^{\star}$ & 43.0 \\
\hline 29 & $30.9^{*}$ & 12.2 & $39.6^{*}$ & 29.7 & 55.0 & 56.6 & 14.3 & 18.0 & $25.9^{*}$ & 18.5 & 53.7 & 52.4 \\
\hline 30 & $36.5^{\star}$ & 11.9 & $53.2^{*}$ & 30.1 & $55.2^{*}$ & 67.6 & 16.9 & 23.5 & $28.8^{*}$ & 21.2 & 60.2 & 54.1 \\
\hline $31+$ & $39.6^{*}$ & 32.6 & $58.3^{*}$ & 50.4 & $57.9^{*}$ & 68.3 & $24.6^{\star}$ & 32.3 & $38.7^{\star}$ & 35.5 & 66.6 & 66.4 \\
\hline \multicolumn{13}{|l|}{ WC (cm) } \\
\hline $70-74$ & 10.2 & 8.0 & $20.7^{\star}$ & 0.0 & 32.5 & 17.4 & $6.6^{\star}$ & 11.5 & $12.0^{\star}$ & 3.2 & 22.7 & 28.7 \\
\hline $75-79$ & $13.2^{\star}$ & 4.2 & $18.8^{*}$ & 9.9 & $33.1^{*}$ & 9.4 & $7.6^{\star}$ & 4.2 & $11.6^{\star}$ & 7.7 & $34.0^{*}$ & 20.5 \\
\hline $80-84$ & $18.2^{*}$ & 4.3 & $24.0^{*}$ & 11.3 & $36.5^{\star}$ & 20.7 & $7.8^{*}$ & 3.7 & $14.7^{\star}$ & 8.4 & $36.8^{\star}$ & 24.4 \\
\hline $85-89$ & 15.6 & 16.7 & $27.7^{*}$ & 19.6 & 34.6 & 35.9 & $9.8^{*}$ & 14.1 & $19.2^{*}$ & 13.9 & 40.9 & 37.2 \\
\hline $90-94$ & $22.3^{\star}$ & 1.9 & $33.7^{\star}$ & 16.9 & $40.9^{*}$ & 27.6 & $14.4^{\star}$ & 18.7 & 20.5 & 18.0 & 49.4 & 52.9 \\
\hline $95-99$ & $26.3^{*}$ & 19.0 & $36.4^{\star}$ & 31.0 & 51.4 & 48.8 & $14.4^{\star}$ & 20.8 & 25.8 & 24.1 & 50.9 & 56.4 \\
\hline $100-104$ & $32.5^{\star}$ & 5.4 & $39.1^{*}$ & 26.0 & 54.5 & 49.8 & $17.8^{\star}$ & 5.8 & $30.4^{*}$ & 21.8 & 57.0 & 52.5 \\
\hline $105+$ & $43.3^{*}$ & 31.3 & $58.6^{*}$ & 43.3 & 60.2 & 62.4 & $26.5^{\star}$ & 37.2 & $41.3^{*}$ & 37.1 & 66.6 & 66.2 \\
\hline
\end{tabular}

* Significant difference between national groups: $P<0.05$

Mexico rose with BMI and $\mathrm{WC}$ as well as age. For both men and women aged $<50$ years, Mexicans had a consistently greater HT prevalence at comparable age, BMI or WC than did Americans. About half the Mexican adults aged $>50$ years had HT, but national differences were not evident at these high prevalences.

The prevalence of abdominal obesity, assessed by WC and taking account of BMI, was much higher in Mexicans, particularly in women, than in the US adults. Thus, if the upper WC cut-off points proposed by $\mathrm{WHO}^{19}$ are considered, i.e. $88 \mathrm{~cm}$ for women and $102 \mathrm{~cm}$ for men, there was a much higher rate of abdominal obesity (21.7\%) in Mexican women - even among those of normal BMI than in US women (10\%), whereas the men had comparable rates (Mexicans $1.4 \%$ vs. Americans 3.0\%).
When the co-morbidities of hypertension and diabetes are assessed, there was a greater gradient in risk in relation to WC than in relation to BMI, particularly with HT (Table 3). However, the greater Mexican prevalences of both DM and HT are still evident for both sexes when account is taken of the BMI and WC values in persons aged $<50$ years (Tables 2 and 3 ).

Table 4 shows the results of factor analysis of WC, BMI, age and height in predicting the prevalence of DM and HT in Mexico. For HT in both men and women, the first factor implies that the most important variables explaining most of the total variance are WC and BMI. In contrast, the second factor implies that age is also an important variable correlating with HT, whereas height is negatively correlated. Thus older adults have higher HT prevalences but

Table 4 Factor loading patterns after orthogonal rotation of principal components for the anthropometric values and age in relation to hypertension (HT) and diabetes mellitus (DM) in men and women in the factor analysis. Each factor (set of variables) accounts for a maximum amount of variance in HT and DM prevalence. Factor loadings are equivalent to a Pearson's correlation coefficient between each variable and the factor. Factor loadings $|\geq 0.4|$ (numbers in bold type), which share at least $15 \%$ of variance with the factor, were used in interpretation and analysis. The value of factor loading indicates the importance of a variable in the definition of the pattern

\begin{tabular}{|c|c|c|c|c|c|c|c|c|}
\hline \multirow[b]{4}{*}{ Variable } & \multicolumn{8}{|c|}{ Factor loading } \\
\hline & \multicolumn{4}{|c|}{$\mathrm{HT}$} & \multicolumn{4}{|c|}{ DM } \\
\hline & \multicolumn{2}{|c|}{ Men } & \multicolumn{2}{|c|}{ Women } & \multicolumn{2}{|c|}{ Men } & \multicolumn{2}{|c|}{ Women } \\
\hline & Factor 1 & Factor 2 & Factor 1 & Factor 2 & Factor 1 & Factor 2 & Factor 1 & Factor 2 \\
\hline Waist circumference (cm) & 0.935 & -0.014 & 0.931 & 0.073 & 0.946 & 0.113 & 0.961 & -0.067 \\
\hline Body mass index $\left(\mathrm{kg} \mathrm{m}^{-2}\right)$ & 0.894 & -0.004 & 0.906 & -0.012 & 0.888 & -0.316 & 0.919 & -0.067 \\
\hline Age (years) & 0.221 & 0.782 & 0.203 & 0.768 & 0.006 & 0.942 & 0.326 & -0.630 \\
\hline Height (m) & 0.248 & -0.757 & 0.137 & -0.798 & 0.661 & 0.388 & 0.130 & 0.862 \\
\hline$\%$ of total variance & 44.6 & 29.6 & 74.5 & 30.8 & 81.7 & 28.7 & 76.0 & 28.7 \\
\hline
\end{tabular}


Table 5 Regional differences in age-adjusted anthropometry (mean \pm standard deviation) and the prevalences of overweight (body mass index (BMI) $25.0-29.9 \mathrm{~kg} \mathrm{~m}^{-2}$ ), obesity (BMI $>30 \mathrm{~kg} \mathrm{~m}^{-2}$ ), hypertension (HT) and diabetes mellitus (DM) in Mexican men and women aged 20-69 years from the National Health Survey, 2000

\begin{tabular}{|c|c|c|c|c|c|c|}
\hline & North & Centre & Metropolitan & South-East & Urban & Rural \\
\hline \multicolumn{7}{|l|}{ Men } \\
\hline Weight (kg) & $77.2 \pm 14.9$ & $73.5 \pm 14.5$ & $74.2 \pm 13.8$ & $69.5 \pm 13.7^{*}$ & $76.0 \pm 15.0$ & $70.4 \pm 13.7^{\star \star}$ \\
\hline Height $(\mathrm{cm})$ & $168.7 \pm 7.1$ & $166.3 \pm 7.3$ & $166.1 \pm 7.2$ & $162.4 \pm 7.5^{\star}$ & $167.1 \pm 7.5$ & $164.4 \pm 7.7^{\star \star}$ \\
\hline $\mathrm{BMI}\left(\mathrm{kg} \mathrm{m}^{-2}\right)$ & $27.1 \pm 4.8$ & $26.5 \pm 4.6$ & $26.9 \pm 4.7$ & $26.3 \pm 4.5^{\star}$ & $27.2 \pm 4.8$ & $26.0 \pm 4.4^{\star *}$ \\
\hline Waist $(\mathrm{cm})$ & $95.8 \pm 14.1$ & $93.3 \pm 13.4$ & $92.9 \pm 12.1$ & $91.6 \pm 14.6^{*}$ & $94.9 \pm 14.1$ & $92.0 \pm 13.7^{\star \star}$ \\
\hline Overweight (\%) & 41.2 & 39.8 & 45.6 & $39.6^{\star}$ & 42.5 & $37.9^{\star \star}$ \\
\hline Obesity (\%) & 24.3 & 19.9 & 19.7 & $17.5^{\star}$ & 23.9 & $16.7^{\star \star}$ \\
\hline HT (\%) & 39.1 & 34.7 & 29.7 & $30.4^{*}$ & 35.9 & $33.1^{\star *}$ \\
\hline DM (\%) & 6.0 & 4.4 & 5.5 & $8.2^{*}$ & 5.5 & 7.2 \\
\hline \multicolumn{7}{|l|}{ Women } \\
\hline Weight (kg) & $69.2 \pm 14.7$ & $65.2 \pm 13.6$ & $65.2 \pm 13.6$ & $62.0 \pm 13.6^{*}$ & $66.9 \pm 14.1$ & $63.6 \pm 14.2^{\star \star}$ \\
\hline Height $(\mathrm{cm})$ & $156.3 \pm 6.4$ & $153.7 \pm 6.6$ & $153.2 \pm 6.4$ & $150.4 \pm 6.6^{*}$ & $154.5 \pm 6.7$ & $152.0 \pm 6.9^{\star \star}$ \\
\hline BMI $\left(\mathrm{kg} \mathrm{m}^{-2}\right)$ & $28.4 \pm 5.8$ & $27.6 \pm 5.5$ & $27.8 \pm 5.6$ & $27.4 \pm 5.6^{\star}$ & $28.0 \pm 5.7$ & $27.4 \pm 5.6^{\star \star}$ \\
\hline Waist $(\mathrm{cm})$ & $94.7 \pm 16.1$ & $93.5 \pm 15.6$ & $92.0 \pm 14.8$ & $92.3 \pm 14.9^{*}$ & $93.3 \pm 15.6$ & $93.5 \pm 15.4^{\star \star}$ \\
\hline Overweight (\%) & 35.3 & 37.0 & 37.7 & $35.7^{*}$ & 36.1 & 36.2 \\
\hline Obesity (\%) & 34.3 & 28.6 & 28.8 & $27.3^{*}$ & 31.8 & $27.7^{\star \star}$ \\
\hline HT (\%) & 28.3 & 26.9 & 23.6 & $24.3^{\star}$ & 26.2 & $26.4^{\star \star}$ \\
\hline DM (\%) & 9.1 & 8.3 & 14.7 & $7.2^{*}$ & 7.9 & 9.4 \\
\hline
\end{tabular}

Data for each region and for the urban and rural subgroups were adjusted to the structure of the Mexican population in the 2000 census.

${ }^{\star} P<0.05$ between the regions using analysis of variance for weight, height, BMI and waist, and using adjusted chi-square test for assessing overweight, obesity, HT and DM differences.

** $P<0.05$ between the urban and rural regions using unpaired Student's $t$-test for weight, height, BMl and waist, and adjusted chi-square test for overweight, obesity, HT and DM differences.

with taller subjects having a lower prevalence. In the case of $\mathrm{DM}$ in men, the first factor explaining most of the variance in the prevalence of DM (81.75\%) includes the variables WC, BMI and height, and the second factor depends mainly on the positive correlation with age. In women, however the first factor has WC and BMI as the important variables contributing to the $76 \%$ of explained variance but the second factor paradoxically includes a negative correlation with age and a positive effect of height.

In both men and women, the percentage of DM and HT risk attributable to excess BMI was at most 51\% for BMI $\geq 23 \mathrm{~kg} \mathrm{~m}^{-2}$. This was reduced to $\leq 45 \%$ for BMI $\geq 25 \mathrm{~kg} \mathrm{~m}^{-2}$ and to $\leq 25 \%$ for BMI $\geq 30 \mathrm{~kg} \mathrm{~m}^{-2}$.

Regional analyses (Table 5) showed that adults in the northern region were taller and heavier with higher obesity rate and greater prevalence of HT than adults in the south-east region, whereas the centre and metropolitan regions had intermediate values; there were no consistent differences in the prevalence of DM, however. The table also includes urban/rural differences, where again the anthropometric indices other than WC were greater in the urban areas as were the overweight and obesity rates. The differences in disease prevalences were, however, inconsistent.

\section{Discussion}

The National Health Survey 2000 is a co-ordinated effort to establish the metabolic risks for the adult population with a special emphasis on adult chronic diseases. This survey should reflect the health condition of the whole Mexican population because great care was taken to have a representative sample. Any skewing of the data because of the absence of men in the households surveyed seems unlikely. The exclusion of the relatively high proportion of men working in the USA from different regions of Mexico might amplify rather than reduce the observed disease prevalences given the high rates of the metabolic syndrome in US Hispanics ${ }^{22}$. However, men in the south-east region have the lowest emigration rate, but the lowest observed overweight, obesity and hypertension rates. Since this was a cross-sectional study, the higher prevalences of chronic diseases in the older groups could be ascribed to age-related changes but we must not forget the possibility of a cohort effect.

It is often pointed out that the populations of Central America tend to be relatively short with particularly short legs. This can then distort the BMI estimates ${ }^{23}$. Sitting heights were not measured in this survey but shorter adults were not selectively classified as overweight or obese and the shorter southern-region adults were less obese than the taller northerners. If an adjustment could have been made for differences in sitting height this would have reduced the estimated BMIs and thereby amplified the observed rate of co-morbidities at each BMI level. In practice both men and women did show a negative relationship of height to HT but the relationship with DM prevalences was positive. Recalculating the Benn index to take account of any distortions in the weight/height relationships did not reveal any advantages in changing the index from $2.0^{24}$.

Any body disproportion should not, however, affect the relationships to WC. Thus early and long-term limitations in height growth - indicative, for example, of poor maternal nutrition and limited postnatal animal protein intake - did not relate to the Mexicans' propensity to DM. 
Other early effects independent of growth in height may, however, be involved. Petry and Hales ${ }^{25}$ have shown experimentally that low protein maternal feeding induces pancreatic changes, with a reduction in the insulin secretory capacity. And it was shown over 30 years ago that protein-energy malnutrition (PEM) in children induced pancreatic damage which seemed, in terms of insulin production, not to recover after several months of rehabilitation and the re-establishment of a normal general body composition ${ }^{26}$.

Table 1 shows that obesity, DM and HT rates are higher in Mexico than those found in the USA about 10 years ago and shows a further accentuation of morbidity rates compared with those found in the urban national survey in 1993 (Fig. 1). Given the particular importance of abdominal obesity as assessed by WC, the greater sensitivity of Mexicans to DM seems to relate in part to the susceptibility to the selective deposition of fat abdominally, as suggested by recent analyses of the metabolic syndrome in Hispanics in the NHANES III study ${ }^{22}$. Once blood lipids as well as the current data on blood pressure and fasting glucose levels become available, the Mexican prevalence of the metabolic syndrome will also be evaluated. Meanwhile, the present findings demonstrate not only the value of WC measurements in predicting the increasing risk of HT and DM in Mexico, but also that there are even higher rates of DM and HT in most Mexicans' age groups than those expected from their rates of abdominal obesity. Using the WC rather than BMI values to screen for $90 \%$ of national cases of DM and HT leads to the choice of $83 \mathrm{~cm}$ for WC in both sexes but BMI as low as $22.0 \mathrm{~kg} \mathrm{~m}^{-2}$ in men and $23 \mathrm{~kg} \mathrm{~m}^{-2}$ in women ${ }^{27}$.

Why abdominal obesity is so prevalent in Mexico is uncertain. It is noteworthy that adult Guatemalans who were stunted in childhood are more prone to abdominal obesity $^{28}$; and Barker et al. also have preliminary data ${ }^{29}$ suggesting that children nutritionally disadvantaged in early life have a predilection to abdominal obesity. Such a propensity may reflect altered imprinting of the hypothalamic-pituitary-adrenal axis ${ }^{30}$, in keeping with Björntorp et al.'s concepts of biological and environmental factors rather than an ethnicity-related genetic basis for the difference ${ }^{31}$. It is also recognised that the prevalences of low birth weight and PEM in Mexico were extremely high in the 1940 s to the $1960 \mathrm{~s}^{32}$ when the current Mexicans under study were born and reared, so their current sensitivity to abdominal obesity may well reflect the consequences of early foetal and childhood programming. The high rates of hypertension with substantial mortality rates from cerebrovascular disease ${ }^{20}$ may also be related to foetal programming but salt intakes are traditionally high, especially in urban areas ${ }^{33}$. Fruit and vegetable intakes, which promote lower blood pressures ${ }^{34}$, are also surprisingly low in Mexico ${ }^{35}$ so these other dietary factors may well also contribute to the greater HT rates at equivalent WC than those in US Whites.
The susceptibility of Mexicans to abdominal obesity, and to DM and HT, now places a greater emphasis on public health measures to enhance physical activity and to change the dietary patterns of this morbidity-prone population. The demand for medical assessment and treatment will continue, for the foreseeable future, to overwhelm both the medical and economic capacity of the health services. The management as well as prevention of these diseases therefore needs evaluation not just in terms of the latest management guidelines produced elsewhere, but also in relation to the medical and other facilities available for coping with such a burden of disease.

\section{Acknowledgements}

The ENSA 2000 (National Health Survey 2000) was financed by the Ministry of Health, the Under-Secretary for the Prevention and Protection of Health and the National Institute of Public Health. The ENSA 2000 Group had the following members: Gonzalo Gutiérrez, Mario Henry, Miguel Ángel Lezana, Gustavo Olaiz, Pablo Kury, Jaime Sepúlveda, Roberto Tapia-Conyer, José Luis Valdespino, Oscar Velázquez-Monroy. They were responsible for the design of the sample frame and questionnaires of the national survey.

Declaration of interests: None in relation to this work.

Contributors: C.P.S.-C. was involved in data analysis and manuscript preparation. O.V.-M. and R.T.-C. of the ENSA group were responsible for the epidemiological aspects of the national ENSA Mexico 2000 survey, as was A.L.-E., who also participated in the analysis and manuscript development. A.B. handled the data analyses and helped with the manuscript preparation; W.P.T.J. was involved throughout the data analysis and manuscript production.

\section{References}

1 Castillo-Salgado C. Análisis de situación de salud en las Américas, 1999-2000. Boletín Epidemiológico/OPS 2000; $21(4)$.

2 Rivera Dommarco J, Shamah Levy T, Villalpando Hernández S, González de Cossío T, Hernández Prado B, Sepúlveda J. Encuesta Nacional de Nutrición (1999). Estado Nutricio de Niños y Mujeres en México. Cuernavaca, Morelos, México: Instituto Nacional de Salud Pública, 2001.

3 Allen LH, Rosado JL, Casterline JE, Martínez H, López P, Muñoz E, et al. Vitamin B-12 deficiency and malabsorption are highly prevalent in rural Mexican communities. American Journal of Clinical Nutrition 1995; 62: 1013-9.

4 Sánchez-Castillo CP, Lara JJ, Romero-Keith J, Castorena G, Villa AR, López N, et al. Nutrition and cataract in low-income Mexicans: experience in an Eye Camp. Archivos Latinoamericanos de Nutricion 2001; 51(2): 113-21.

5 Sperduto RD, Hu TS, Milton RC, Zhao-Yao L, Dawsey S, Guo WD. The Lixian Cataract Studies: two nutrition intervention trials. Archives of Ophthalmology 1993; 111: 1246-53.

6 Encuesta Nacional de Alimentación y Nutrición en el Medio Rural (ENAL 89). México: Instituto Nacional de la Nutrición Salvador Zubirán (INNSZ), 1989. 
7 Encuesta Nacional de Alimentación y Nutrición en el Medio Rural (ENAL 96). México: Instituto Nacional de la Nutrición Salvador Zubirán (INNSZ), 1996.

8 Food and Agriculture Organization (FAO)/World Health Organization (WHO). Requirement of Vitamin A, Thiamine, Riboflavin and Niacin. FAO Food and Nutrition Series No. 8/WHO Technical Report Series No. 362. Geneva: WHO, 1967.

9 Secretaría de Salud. Mortalidad. Principales causas de mortalidad general. Estadísticas Vitales. Estados Unidos Mexicanos: Secretaría de Salud, 1999.

10 Encuesta Nacional de Enfermedades Crónicas (ENEC) México: Epidemiología, Secretaría de Salud, 1993.

11 Arroyo P, Loria A, Fernández V, Flegal KM, Kuri-Morales P, Olaiz G, et al. Prevalence of pre-obesity and obesity in urban adult Mexicans in comparison with other large surveys. Obesity Research 2000; 8: 179-85.

12 Duggirala R, Blangero J, Almasy L, Arya R, Dyer TD, Williams $\mathrm{KL}$, et al. A major locus for fasting insulin concentrations and insulin resistance on chromosome $6 \mathrm{q}$ with strong pleiotropic effects on obesity-related phenotypes in nondiabetic Mexican Americans. American Journal of Human Genetics 2001; 68: 1149-64.

13 Hales CN, Barker DJP. The thrifty phenotype hypothesis. British Medical Bulletin 2001; 60: 5-20.

14 Valdespino JL, Olaiz G, López-Barajas MP, Mendoza L, Palma $\mathrm{O}$, Velázquez $\mathrm{O}$, et al. Encuesta Nacional de Salud 2000. Tomo I: Vivienda, Población y Utilización de Servicios de Salud. Cuernavaca, Morelos, México: Instituto Nacional de Salud Pública, 2003.

15 Instituto Nacional de Geografía y Estdística, www.inegi gob.mx/

16 Report of the Expert Committee on the Diagnosis and Classification of Diabetes Mellitus. Diabetes Care 1997; 20: 1183-97.

17 American Heart Association science advisory guide to primary prevention of cardiovascular diseases: a statement for healthcare professionals from the Task Force on Risk Reduction. Circulation 1997; 95 2329-31.

18 StatSoft, Inc. STATISTICA for Windows [computer program manuall. Tulsa, OK: StatSoft Inc., 2000.

19 World Health Organization (WHO). Obesity. Preventing and Managing the Global Epidemic. Report of a WHO Consultation on Obesity, Geneva, 3-5 June 1997. Geneva: WHO, 1998

20 http://www.paho.org/English/HCP/HCN/IPM/svn-asmrtables.htm

21 US Department of Health and Human Services. National Health and Nutrition Examination Survey III, 1988-94 CD-ROM Series 11 No. 1. SETS Version 1.22a. Hyattsville, MD: National Centre for Health Statistics/Centers for Disease Control and Prevention, revised October 1997.
22 Ford ES, Giles WH, Dietz WH. Prevalence of the metabolic syndrome among US adults: findings from the third National Health and Nutrition Examination Survey. Journal of the American Medical Association 2002; 287(3): 356-9.

23 Norgan NG, Jones PRM. The effect of standardising the body mass index for relative sitting height. International Journal of Obesity and Related Metabolic Disorders 1995; 19(3): 206-8.

24 Benn RT. Some mathematical properties of weight for height indices used as measures of adiposity. British Journal of Preventive \& Social Medicine 1971; 25: 42-50.

25 Petry CJ, Hales CN. Long-term effects on offspring of intrauterine exposure to deficits in nutrition. Human Reproduction Update 2000; 6(6): 578-86.

26 James WP, Coore HG. Persistent impairment of insulin secretion and glucose tolerance after malnutrition. American Journal of Clinical Nutrition 1970; 23(4): 386-9.

27 Sanchez-Castillo CP, Lara Esqueda A, Berber A, Velázquez Monroy O, Tapia Conyer R, James WPT, Encuesta Nacional de Salud (ENSA) 2000 Working Group. Anthropometric cutoff points for predicting type 2 diabetes mellitus and hypertension in the Mexican National Health Survey 2000. Obesity Research 2003; 11(3): 442-51.

28 Schroeder DG, Martorell R, Flores R. Infant and child growth and fatness and fat distribution in Guatemalan adults. American Journal of Epidemiology 1999; 149: 177-85.

29 Barker DJ, Hales CN, Fall CH, Osmond C, Phipps K, Clark PM. Type 2 (non-insulin-dependent) diabetes mellitus, hypertension and hyperlipidaemia (syndrome $\mathrm{X}$ ): relation to reduced fetal growth. Diabetologia 1993; 36: 162-7.

30 James WP. Long-term fetal programming of body composition and longevity. Nutrition Reviews 1997; 55(1 Pt 2): S31-41, discussion S41-3.

31 Björntorp P, Holm G, Rosmond R. Hypothalamic arousal, insulin resistance and type 2 diabetes mellitus. Diabetic Medicine 1999; 16: 373-83.

32 Peschard A, ed. Nutriología 1995; 2(2 Diciembre) [trimester journal of the National Institute of Nutriology (now National Institute of Medical Sciences and Nutrition Salvador Zubirán), Ministry of Health, Mexico].

33 Sánchez-Castillo CP, Solano ML, Flores J, Franklin MF, Limón $\mathrm{N}$, Martínez del Cerro V, et al. Salt intake and blood pressure in rural and metropolitan Mexico. Archives of Medical Research 1996; 27: 559-66.

34 Sacks FM, Svetkey LP, Vollmer WM, Appel LJ, Bray GA, Harsha D, et al. Effects on blood pressure of reduced dietary sodium and the dietary approaches to stop hypertension (DASH Diet). New England Journal of Medicine 2001; 344: $3-10$.

35 Batrouni KL, Chávez A. Modernización de la dieta urbana y enfermedades cardiovasculares. Revista de Investigacion Clinica 1986; 38(Suppl.): 21-6. 